\title{
Study on the Lantern Culture of the Hakka Ancestral Land Ninghua*
}

\author{
Tao Zhang \\ Overseas Education College of Xiamen University \\ Xiamen, China 361102
}

\begin{abstract}
As an intangible cultural heritage, the Ning-Hua Hakka lanterns represented by high ceiling lamps have unique research value and significance. In this paper, a thorough investigation including lanterns of Hakka culturewas carried out. It traces the origin of the Hundred Brid High Shed Light in Huai plateau and analyzes the cultural characteristics of the Birds High Shed Light and their creative elements and talk about the relationship between the Hakka light and social life. At last, this paper willook at the outlook of theHakka lanterns aiming at broadcasting the Hakka spirit.
\end{abstract}

Keywords-Hakka; Ninghua; lanterns; intangible cultural heritage

\section{INTRODUCTION}

The lantern, which originated from folk lanterns, is a kind of lighting tool. After continuous improvement and decoration, people feel that the lanterns can bring light, which is a good gift for filial piety and worship of the gods, because their forbears and gods still need light in the heaven. So it became a ritual for entertaining offerings for god, through the long history of cultural change, increasing its content and varying its form, with its function changing from entertaining the gods gradually into entertaining the folks, which is evolved into a kind of folk culture and entertainment activities, thus become an indispensable project building festival atmosphere.

Ninghua Hakka festive lantern is represented by the high ceiling lamp, originally called "the hundred birds paying homage to phoenix" lamp, which is the most lasting and highest of the lantern and is known in the border areas of Fujian and Jiangxi provinces. The colorful flowers and birds of the whole lamp are colorful and vivid, which fully demonstrates the superb quality of the paper-cutting and painting. It was declared in Ninghua county, Fujian province and was listed in the first batch of municipal intangible cultural heritages in Sanming city. At the same time, it was also proposed to declare the intangible heritage protection project of Fujian province.

\section{NINGHUA HAKKA FESTIVE LANTERN CULTURE.}

Hakka lanterns combine the characteristics of the ancient Chinese Han lamps and lanterns along the way. Through the constant practice, generations of paper artists make it vivid,

*This article is a phased achievement of the "Study of Ninghua Hakka Art as an Intangible Cultural Heritage" of the Social Science Planning Project of Fujian Province. colorful, rich in content and diverse in varieties. Being a traditional handicraft art collection, it is a combination of weaving, paper-cutting, painting, calligraphy, lamp linking and poetry.

The recreational activities of the lanterns are reflected in the activity of demonstrating lights. There are large, mediumsized and small differences in the activity of the tour lamps of Hakka people. The large lanterns are large-scaled, organized and more ornamental; medium - sized lanterns are flexible, and are more entertaining; small festive lanterns' designs are various, they are easy to hold up and are more ornamental.

\section{A. Colorful Small Lanterns}

Small lanterns are usually of holding type or hanging type. The former refers to the homemade lanterns, or the paper (now mostly plastics) products bought from the market, mostly are animals and birds, and worms or the fish or flowers. When the festival comes, the child lights the candle in the lamp (or the small light bulb of the dry battery), holding the lamps, running and playing, which fully displays the innocence of the childhood and the beauty of the lamp decorations. It is a different picture to have a group of the children, parading like a long dragon. The latter has the largest number of "big red lanterns", people generally like to hang them in front of the big gate to increase the festive atmosphere. There is another kind of "palace lamp" that hangs in the hall, which is also quite representative. It was a two six-prismatic frame with different sizes of bamboo. The larger one was shorter and was on the top, the smaller one was longer and was on the above, forming into a whole like the old-fashioned Chinese character "Buy". The exterior is made of white paper, drawn with beautiful pictures on six sides, or various kinds of flowers and birds, or various figures, extremely delicate and vivid, and looks amazing in the light of the candles. Fastidious people used small wooden sticks to make frames. At the bottom it is connected, outside it is covered with silk, seeming more delicate and elegant. There is also a kind of "walking horse light", which is also made of bamboo and weaved into cylinder shape. The lantern is coated with white paper, and the surrounding clipboard is decorated with exquisite pictures. The lamp is equipped with a rotating disk with a central shaft, and a cardboard cutout of the civil service, martial arts, knights, galloping horses, etc. hanging around the rotary table with a fine line. As long as there is candle flame in the lamp, the heat will go up and make an impulse to push the window-shades. As a result, the silhouette of the various images hanging on the 
edge of the disc will appear on the surface of the white paper, like a shadow. The pedestrian stopped to watch, so the street merchants loved to hang out the lanterns, thus forming a landscape. Yanxiang has a special supply of six-sided lights, light bulbs and other lights for hanging at the entrance of the village. During the period of the temple fair, the lanterns of various sizes and lanterns are made up of a world of lanterns, quiet or moving, forming a unique style.

\section{B. Flexible Medium-sized Lantern}

The production of medium-sized lanterns is relatively simple, and the preparation is faster. There is no need for a lot of expenses, so it was usually made by amateurs of a group. This type of lamps has the nature of recreational performance, the time of the lamp parade is generally longer, namely from the first ten days of the festival(festivals like the temple fair period, the Ghost festival on the 15 th of July, or the water lantern festival on the 15th of October, mostly the Lantern festival on the 15th of January)In ancestral hall or incense hall, there is first the ritual of sacrificial lighting ceremony, then to worship ancestors, gods, complex or simple, different places have different habits. Then they started to go to the village, and they went out once every night. For example, the dragon lantern (with the haw dragon lantern, the paper dragon lantern), the running horse lamp, the dry boat lamp, etc., the workers are lean and flexible. Once they go to a village or a place, they must perform once. The stage has not to be too big. A suntan ground is just fine. As the light parades are usually accompanied by the special brand of Ninghua Hakka trumps, the parades are usually very lively, and the children in groups are chasing after each other. It is a blessing for the villagers of mountain villages in remote and isolated conditions to see such a walking light show. What's more, the words and paintings on the lighting lanterns, the speech and expressions of the performance are all auspicious words that cater to people's good wishes, such as good luck and agreeable wishes, the full house of many generations, a good harvest, and the prosperity of the farm animals, etc. Everybody loves to see, everyone loves to listen, especially with the children, no matter when do the lanterns parade comes into the house, they always shout "the dragon lanterns come into the house, buy the field and build a new house", which makes everyone joyful. Even the "stem dragon lantern" of the youth organization is often talked about, all of the people will applaud. The so-called "stalk dragon lantern" is to make the dragon ball, the dragon head, the dragon tail and some dragon body with straw. In addition to the dragon ball being used as a guide, a straw rope is used to connect each part of the dragon body so that it can form a whole and not broken. In the dragon ball and the dragon body parts, there are incense fire everywhere. When the night falls, the dragon dances, the fire was seen shaking, appearing an image of a fire dragon. When they do the performance, the dragon turns up and down, and seems to swallow the beads. How beautiful! On the day after the festival, the villagers will voluntarily give red envelopes to visitors. The so-called "thank the lamp" is a kind of ending ceremony. Usually the villagers will send the lamps to the river to burn, and then to pray for the good weather and the peace and happiness. If it is a dragon lantern, the sacrifice is called "dragon pray". After the dragon lanterns are finished, villagers will choose the time to worship and pray on the dragon mountain; and then every day they to in groups to the villages to do the "dragon dance". At the end of the activity, it is necessary to tear down the decorations and scales of each part of the dragon body to the riverside to incinerate, leaving the trunk to the next year, which is called "thank the dragon". If it is the "stem dragon lantern", the whole of the dragon will be burned and ashes spew into the water, meaning "dragon return to the sea", commonly known as "thank the dragon". The lights parades above are mainly performances, some even have words and songs, which is the same as stage performance. For example, running a horse lamp, a dry boat lamp, etc., is not so much a "lamp", but is simply to take the stage of the related folding scenes to the suntan. This kind of performance can be out of the village, out of the country, everywhere. They are always welcomed. The villagers are looking forward to the next year's performance. These lanterns express Hakka people's longing for the future, longing for the peaceful life of the peasant family, increasing the enjoyment of the villagers during the festival period, and strengthening the clan affinity of the Hakkas.

\section{The Large Lanterns with Distinctive Features}

Large festive lantern activities are different from small and medium-sized lanterns, which are very large and expensive, and must be organized. This kind of lamp has relatively unique style and theme color in different places. The so-called relative uniqueness is due to the fact that it still retains the common theme of reproduction, family and fortune, and the theme, content and form, but has a big difference in subjects, contents, and forms. For example, high tents lamp in Huai plateau is known as the "little, high", "lights" in the time of Zhiping make an army array with civil-military art models, Cao fang's "lights" slot is also called the "bench" dragon, with characteristics of many plates and long dragon; the "lights" memorial arch of the wall changes from silent to voiced and was immerged with the folk dance. All of these, almost all of them, are patents of different places, and these large lanterns are basically prepared for the local "session", which is the period of the meeting, which is called the temple fair. In Ninghua, the Hakka people lived in ethnic groups, almost a village are of the same family name. The marriage is in the village, relatives are far away from home. Due to the busy farming, ordinary contacts are very limited. Only during the "session" of the lunar New Year, or during other temple fairs, friends and relatives will come to visit, and small business vendors will gather. The village organized acting, gods parade and lanterns parade, entertained both the visitors and themselves. Some will stay up all night, almost every family are visited by many guests. It is an important time for Hakka people to contact with each other. It is a good opportunity for Hakka people to enhance their emotional cohesion.

The festive lantern of Ninghua Hakka is cheap and beautiful, and the materials used are very ordinary. Commonly used are bamboo, paper, sticks, straw, candles, incense, and oil string. In addition to the paper dragon lantern, which is using ramie cloth to cover the connection, cloth is seldom used. As a result, the lanterns made are light and easy to carry. But in the process of the handcrafts, it is high demanded, and is called great attention to appearance modeling: exquisite carving, 
engraving, writings and paintings. "Paper zappers" are almost omnipotent: whether it's a bird or a fish, a bird or an animal, or a geometric pattern, an abstract shape; whether it's a drama or a labor scene, all can be imitated perfectly. The calligraphy and painting poems ornaments are just right, which is amazing. Even if it is a self-braiding "stem dragon lamp", the image is quite realistic, the overall proportion is coordinated, giving the viewers a look in nature. To some extent, this reflects the aesthetic consciousness and artistic interest of the Hakka family, which is precisely this kind of consciousness and interest that promotes the continuous improvement of the art of Ninghua lantern.

\section{THE ORIGIN OF THE HUNDRED BIRDS LANTERN IN HuAi Plateau}

The high ceiling lamp is one of the typical lanterns, and the high ceiling lamp of Huai plateau is also known as the phoenix lantern, which is the representative of the high ceiling lamp. According to "Ninghua county": "... The high ceiling light of Huai plateau is very distinctive. Using sticks and bamboos to form the body, the lanterns are usually 5-7 meters high. Outside was covered with paper animals. Being lighting and shining, colorful animals are waving under the light when it was carried in a parade during night.

Huaitu, now an administrative township in Ninghua county, is 27 kilometers away from the county seat, and its township government is located in Huaiyang village. In ancient times, Huaiyang village was the jurisdiction of the dragon, which belongs to the ancient stone wall, 7 kilometers away from the stone wall. Due to its location was in west of Ninghua, people called it the Huaitu area of the west. Because the Huai plateau has a waterway to travel to the lower reaches of the Yangtze river, in the case of traffic congestion, the Huai plateau has become the stone wall and even Ninghua's export town.

God seems to be trying to test the wisdom of the Ninghua people. On the one hand, it arranges a remote and secluded geographical environment for you; on the other hand, it gives you the vast and dense forest, making its timber resources extremely rich, especially fir wood and big lumbers. At the end of the Sui dynasty, it was seen that the resource advantages were available to him, so he "cut down trees and made a raft and sail to Wu". ${ }^{2}$ The Ninghua River is divided into the Min river, the Han river and the Gan river. By using the river system of Gan river, Wuluojun took the timber raft and then connect them. They sail from the Huai plateau of Xixiang to the Heng river, then into Jiangxi Gan river, then Nien river, even to Yangtze river, and then to Yangzhou and other places to trade. Despite the hardships of this relay race, it is finally possible to find a way to the lower reaches of the Yangtze river. And the story of the high ceiling lamp is also connected with this channel.

\footnotetext{
"The Chronicle of Ninghua County ", compiled by the Ninghua County Chronicles Committee, Fujian People's Publishing House, 1992. "The Chronicle of Ninghua County ", revised by (Qing) Li Shixiong, prepared by Ninghua County Chronicles Committee, chiefly compiled by Fujian Provincial Local Records Compilation Committee, Fujian People's Publishing House, 2012.
}

According to the legend, in the Southern Song dynasty, there was a man named Liu, who was a pioneer in the timber business, and took advantage of the water transportation channel in history. From the Heng river to the Yangtze river, he was transported to Yangzhou and other places to trade. Once he had just arrived in Yangzhou unconsciously, the emperor was selecting high qualified giant trees to build the palace. The Ninghua's fir timbers are impeccably selected as the finest materials. As a result, the wood merchant provided a steady stream of timbers supply to ensure palace building, he has also become a hero and praised by the emperor. When the emperor asked him what he wants for a reward, the wooden merchant lnoticed that there are many colorful lights hanging in the palace. One of them was a phoenix lantern, which could be carried around on people's shoulders, and the birds would swing as if they were alive. He thought that if he could get the lanterns spread to Ninghua, to some extent he would have done a good thing for his hometown. So he asked for it. The emperor was happy, not only did he promise him on the spot, but also give a special command to the artisans to go along with the wood merchant to build lanterns in the Huai plateau.

When lanterns were finished, people can see red swing along the wind, 2 words "imperial edict" were emblazoned on. It is true that the lanterns make the world different. According to the legend, when the lanterns first came to the place, the light was too bright to frighten the farm animals to no calls. It is even more surprising that since the lantern honored by the emperor has come to Huai plateau, the local areas saw a fast flourishing. There are more and more Hakka people surged in, and the lanterns activities are more exciting. The lanterns are getting increasingly more, and each one has the "imperial edict" on, the lanterns are famous all around the place. Later, the situation was out of control, and the two words of "imperial edict" were everywhere, there was a suspicion of cracking down on others counting on the emperors and will affect the good neighborly relations. So, they decided to reduce the number the lanterns and make them higher, which also makes them unique. Since it is as high as a high ceiling building, the local people call it the high ceiling lanterns.

\section{The ARt FeAtures OF High CEILING LAMPS}

\section{A. The Lamp Is High and the Small and the Big Parts Are Together}

The high ceiling lamp, originally called "birds of the phoenix", is a giant of up to 15 meters high, with a site area of 4.5 square meters. The bamboo strips, which are broken open by Hsinchu, are arranged in a frame of lamps, usually seven layers, which are stacked on top of each other. Only few timbers were used as the body to be fixed on the frames. The front is full of separate paper, flowers, insects, birds, animals, and other small colored lights, all wrapped in paper twisted strips. In fact, it is a multi-lamp combination, which is often referred to as "mother and child lamp", with the "mother" lamp as the main body and the carrier, and the sub-lamp is used to shape the monomer image as the content. On the outside, the paper is coated with glossy paper, and colorful paintings are used to set the interrelation of the children's lamps in the background of the mother lamp. The wonderful thing is that 
the method of assembly is just right, not only to make full use of the elasticity of the bamboo, but also to use the natural inertia of the moving. The children's lamps are either hanging out of the mother's lamp, or they are attached to the mother's lamp, some are hung, some are attached, some are inserted, some are inlaid. Each child's lamp has a right place to function. As long as you lift the frame, characters that can fly were just like they were flying, those that can walk were just like they were walking. All the lanterns are vivid and alive, forming a colorful three-dimensional image. The skill of the paper is amazing! The high ceiling lamp is carried by eight people, and the lamp will be lifted with ox's oil, thus is bright and radiant. There is a special man to light the candle flame in the lamp body to keep it bright. Due to their chassis have different inertia and often caused the lamp body to swing back, they twitch two thick ropes and two long poles on both sides. The thick ropes were taken by two people in front of the lantern, and the two long poles were hold by another two people at the back of the lantern to make the body stable. From a distance, the lantern looks like a lighthouse in the boundless sea, it is especially dazzling, like pointing out the maze. It is said that there is a hint of the spirit of the gods.

\section{B. Rich in Content and Vivid in Image}

Ninghua high ceiling lamp is famous for its high brightness and dynamic movement. The early content was dominated by the happy and auspicious atmosphere of the birds and the phoenix, and then gradually appeared the grouping scene with the layer as the unit, the light body also appears in five to seven layers of different structure, so there are high, medium and short specifications. Before liberation, at the temple fair in the city, the goddess of the Mazu was accompanied by three high and low ceiling lights in the escort. Each group can have a relatively independent meaning, and some of them show the prosperity of a good harvest and the farm animals, thus to pray for the good harvest in the coming year. Some show historical legends, folk anecdotes, inspire future generations to learn from the history. Some show the birds and animals, and flowers, thus pray for the good luck in the future. The overall expression is of people's desire for blessing, the ideal of settling down. Many of them are the traditional Confucian thoughts, known as "the loyal and faithful", "to rescue mother out of the mountain", "tang monk", "Yang army" and so on. The content is rich and extensive, involving different aspects and parts of people's lives. The image is vivid and lifelike. The dexterity of the birds, the ferocity of the beast, and the behavior of the characters are all embodied in the simple appearance of the small colored lights. Also, there is the usage of color, make the person has the feeling as if they were facing a realistic scene. As they carried out their excursion, the lights flashed on the background to make the lanterns suddenly become vivid. As if the birds were flying in all shapes, and all the different beasts were moving through; "Yang army" rode the horse to kill, and the enemy will flee in all directions". The great axe of "rescuing the mother in the mountain" was felled by huge boulders. The macro layout of the whole lamp is big, and the local image is perfect. It leaves an impression that cannot be forgotten.

\section{The Technique Is Ingenious and Sophisticated}

The high ceiling lamp is a seven-story tower block with a height of more than ten meters. Also, the light parade is often carried out at night, if there is no strong lighting, it is very difficult to show it. In the absence of electric light, it was a big problem. Because the candles that are commonly used in the brightly lit lamps are too hot to be dewaxed, quickly they would extinguish. And a homemade oil series, oil production appeared. It is a flash paper towel to rub into several feet long bars, with a moderate proportion of vegetable oil (some butter) and sulfur in POTS to try them. Also, they also install the iron clips at each light point of the lamp body to hold the oil string to ignite. Immediately, the flame is ablaze, no oil leakage or fire quenching, which has an excellent effect. In order to enhance the light transmittance, the laminated paper is made of thin, smooth and fine quality dye. Due to the use of these special materials, the whole lamp body is brilliant and radiant. Together with the depiction are its artistic images, the technique is summarized, the spirit is prominent, and the physical features are prominent. For example, the four legs of a galloping horse, with only two pieces of bamboo bent to form the backbone, thus creating its strong appearance. Displayed in the green mountains and waters, the image is pretty like a horse flying over the flat river, adding more movement to the illusion of the light, thus is better. The light here adds lighting technology into the paper in the form of art and graphic art, to achieve the perfect combination, drastically enhanced the appeal for the topics. The audience can get affected by the moral influence in their endless visual enjoyments. Its artistic technique is unique, the craftsmanship is excellent, which is impressive and lasting. And that's the specificity of the ceiling lamp. Therefore, form the eighth to the 15th day of the first month in Chinese lunar calendar, the lantern parade activities are very popular. With the help of the brand gong and drum to create a warm atmosphere, the local villagers also feel endless joy, together with their relatives and friends, and making the high ceiling light is almost the patent of the Huai plateau.

\section{THE HIGH-SHED LAMP IS BROUGHT FORTH NEW}

\section{A. The New Concept of "Hakka Monument"}

Sanming city, in 1996, held the thousand lamp bloom festive lantern show. Among the giant lanterns of distinguishing features, they select lanterns of Huai plateau for the exhibition. They discussed the production plan in advance, named it as "Hakka monument" shed light. In the 30 days' exhibition, this one has the largest number of audience, and received the warmest welcome. People have entertained their eyes in the exhibition, and the lanterns was praised the first place for its uniqueness. The whole lamp retains the traditional basic pattern, but infuses new ideas into the concrete design: In appearance, the square pillar is changed into a pagoda shape; In the picture, change the front lamp to the surrounding cloth lamp; In the form, change the carrying of the lamp tour into for the static viewing lamp; In the power, change the weaving powered into the electric powered. In lighting, candles are replaced by electric lights; especially in the content, the traditional theme is the Hakka theme, which makes the content richer, the image is more vivid, the theme is more positive, and 
more ornamental. It is a good demonstration for the purpose of education in entertainment, which promotes the Hakka spirit. The high ceiling lamp of the Hakka monument is limited by the indoor exhibition hall. The lamp is 4 meters high and 2 meters wide and has seven layers. The first layer of light body is a pedestal, with double dragon playing beads to ornament "imperial indict". The second light body is decorated with folk paper-cut, and the "smart people" and "lucky place" are introduced in this paper. The specific contents include the five great southwards in Hakka history, and the reason, period, region, route and distribution of the migration were introduced in detail. This paper introduces the Hakka celebrities, among whom is Zhang Xianzong, and Huang Shen, one of the eight eccentric artists in Yangzhou; Yi Bingshou, great handwriting artist who is known as the "the southern $\mathrm{Yi}$ and northern Deng". It also introduces the first names of the 19 Hakka people who moved into Ninghua in the early days. The third layer of light is a rotating lantern, which is an attempt to put other patterns into the high ceiling lamp. Before, the turn of the original lantern was driven by the hot air of the windmill, now was by the electricity. The "Hakka family greeting picture", which reflects Hakka folk custom, can be more conducive to the expression of this festive and lively scene, indicating the charm of the hakka style. The fourth floor and the fifth floor are the lamp's body is the mother-child structure, 200 surnames of the hakka ancestral were left images displayed among them, with the name of the lamp was scripted in Yi's style on, pretty eye-catching. The sixth layer and the seventh layer have an implied meaning of Hakka cradle, the lamp body metaphor with the earth at lamp cap, show that Hakka people is the reproduction of tens of millions of people, and the distribution of the 84 countries and regions, is bitter fleabane bitter fleabane vigorously develop rapidly. The whole lamp body is brilliant, bright, rich in content, the theme is bright, and has played a good role in promoting Hakka culture. It can be said that this is a major reform of the traditional lanterns, which opens a way for the development of lanterns.

\section{B. The Modern Element of "Family Planning and Blessing"}

The success of the "Hakka monument" promotes the further transformation and sublimation of the high ceiling lamp. Both the theme and the artistic means constantly break through the original pattern and inject into them modern elements. In 2003, a family planning volunteer Huang Ruihai held his celebration of his seventieth birthday. He didn't treat or receive gifts but held a special light exhibition of large-scale in the culture square with the money from his sons and daughters, costing him nearly 20000 yuan. That night, the exhibition achieved unprecedented success. The scale is so large that has never been seen in Ninghua. Exhibitions of lanterns were all injected with the content of the propaganda of family planning, and exhibited as a main body, the "blessing family planning" high tents lamp has seen any changes and improvement on the basis of the high ceiling lights "Hakka monument". It retains the basic features and hierarchical structure of the pagoda but its contents and expression methods are bold and innovative. The first is that the materials of the body are stronger, and almost every layer forms a stage for performance; what's more, the two words "imperial edict" were changed to the blessing word "family planning", this is a bold innovation taking challenge to the traditions, making a person suddenly awakened from traditional high ceiling lanterns, transformed and fresh; the third is to use the sound, light, electric and other modern technology means in the lanterns so it can make sound, light, and can automatically rotate without depending on the swing of the light, and can be placed on the ground to watch. In addition, music, dance and other artistic means have been added, so that people can be integrated with lights, lights with dance, family planning with traditional Hakka culture. Its magnificence and variety are rare, and the exhibition has caused an unprecedented stir.

The high-ceilinged lamp, which is planned by Huang Ruihai, is 13 meters high, with a total of six floors. With the top layer of the swan there is seven floors together. The first floor is a quadrilateral with four big Chinese characters "family planning blessing" instead of "imperial edict", meaning the innovation of the high ceiling lanterns. The second layer is about the "butterfly", with the scenes of the butterfly dancing in the flowers and the harmonious family. The third layer is the drum lantern "Mulan studying the sword", using the folk "iron story" technique to put the six girls on the lantern. Among them, four are shouldering a big drum, one is hitting the drum at the back and one is singing and dancing in front of the drum, which proclaiming the new idea of sexual equality. The fourth layer is the electric rotation of the octagon lantern, "give birth to less children and lead a happy life", inside are four small turning light with specific contents on each. The fifth layer is basket lamp "A Girl Splitting out Flowers". A young girl is holding flowers, standing on the rotating basket along the circumference, giving the audience flowers around the lamp body, showing respect to rural families which has two women having ligations. Layer 6 is the combination lamp named the "family planning". On the top of the eastern Huashan cents, seven stars sparkle red light, the pagoda lamp is radiant, a swan is spreading its wings and flying to the distance surrounded by colorful banners.

The development process of Ninghua lantern culture has gone through the evolution from static to dynamic, from silent to sound, from viewing lights to watching people and lights, lights and songs, and lights and dance. The content also moves from the traditional theme to the modern fashion, the structure from the monomer to the combination, form from small to large and small, materials from simple to complex, even modern sound, light, electricity and machinery are universally adopted. In particular, it seems to be necessary to infuse into them some of the modern elements. Since it is high and large, the strong light and rotation can enhance the effect. With the evolution of The Times, the appreciation requirements are also improving. The process of change is inevitable with the revolution of the time and people's aesthetic demand. This kind of cultural and creative transformation, embodies the pragmatic spirit of Hakka people, inspiring the unconsciously educational effect on lanterns culture. As result, they make lanterns culture keep pace with the time and have more vitality, proclaiming to generations and enduring. It should be said that the Ninghua Hakka family has written a great deal of innovation in the culture of Ninghua lantern culture. 


\section{THE RELATIONSHIP BETWEEN HAKKA LANTERN CULTURE AND HAKKA SOCIAL LIFE}

\section{A. Hakka Lantern Culture Is a Product of Immigrant Life}

Hakka ancestors are from the north of the Yellow River and the Yangtze river efficiencies. Due to the evading from the war and famishment, they have to migrate to the south in a large scale again and again. During the long time and hard efforts, they finally settled down on the border of Jiangxi, Fujian and Guangdong. The stone wall became the ancestral land and cradle of their continued southward migration, and gradually formed the Hakka people system in its central region. Therefore, scholars also called the stone wall a Hakka holy land or a transit station. Although there were immigrations extended to Guangxi, Hunan, Sichuan and other provinces and southeast Asia and other countries of the word, but the Hakka culture and its lanterns formed in stone wall formed a unique, far-reaching Hakka spiritual wealth.

Hakka culture is actually an immigrant culture. Immigrant culture has a strong sense of self-protection. In order to keep clansmen gathered but not scattered in the form, to have the same direction and value in ideology to fight against the outside world together for their survival, of the ideological work, the relatives of Hakkas are particularly hard to disengage, and their affinity is particularly profound. The clan is an invisible commander and is with high authority. All should take the interests of the clan first and all activities are distinguished by whether they are from the same family. Many Hakka people are making a living outside for many years. But once the family has something to do, no matter how long the journey is, they have to come back day and night. In every festival, we have to calculate the distance ahead of time and get home on time. On the way, if we met people with the same family name, we take care of each other more heartfully. Like the life and work, Hakka people's culture and their lantern are all of the same kind. No matter what kind of the light is, no matter how large or small, they are always arranged with the same room or the same clan as the unit and can only work in the same room or the family life scope. First of all, the elders, senior citizens of the ethnic group will host the meeting, raise funds, arrange staff, and finally agreed on performance time, location and so on. After the lanterns are made, they will have to give the light ceremony, tell the ancestors first and then start to go out for the parading, even the dragon light which has the most activities in festivals. In the event of a major holiday, such as the first month of the lunar New Year, in addition to the large lights tour of all the families in the village, each family should also be attended with their own lanterns. When the family is concentrated on the parade, there is often a comparison of who is good and who is bad, which promotes the improvement of the quality of the lanterns. So Hakka lanterns activities are not simple festival entertainments, but contain strong family celebration psychological means and shows strong competitive mentality, causing Hakka people have a close clan concept and making the Hakka spirit more promoted. Therefore, the lantern culture plays an important role in the cohesion of the Hakkas people.

Raising large-scaled lanterns activities asks for many financial and material resources and manpower. To ensure the scheduled lanterns activities held on time but not increase the burden of the villagers, this part of the cost comes from the "progenitor compensation" left behind by ancestors. The socalled "ancestral compensation" is the family property of the ancestors. When the family separates into smaller parts, the ancestors will leave out some of the land in advance for the public benefit of the later generations. For example, if you can go to the school, your income from the rent of the land will be increased with the increase of your tuition fee, and your family will not have to worry about it. When you graduate or drop out of school, the land will be taken back. At that time, there were many students who went outside for further study, almost all of them were supported by these rents. There is also the famine relief. During the interval of harvests of grains, people can get grains from the warehouse. After the harvest of the autumn grains, there will be no interest for the harvest of grains. Thanks to this, the poor children will not be ruined. What's more, expenses for the performance on Tomb Sweeping Day, the dinner party and important festivals like the gods parade and light parade are all from the rents of these land. In other words, they rent the land for common expenses. If the land is not rent, they will be cultivated by their descendants in turns, who do the farming on the land will shoulder the year's public events. There is also organizational regulation in the family. Under the condition of small scale and low level of Hakka farming production, this organizational form of the family system solved problems of the descendants' literacy, survival needs and desire for entertainment, etc. in a certain extent. Each lantern activity is a review of the family's kindness and merit, so the drawbacks of the family system do not affect its vitality and constancy. The idea of the Hakka clan is deeply rooted in the hearts of the people, and it has been passed on from generation to generation, so that the people will be more cautious in their pursuit of their ancestors. They honor their ancestors and unite and forge ahead to achieve integration. In this sense, the lantern cultural activities have undoubtedly become one of the strong magnetic fields of Hakka cohesion.

The Hakka ancestral land was remote, and in the primitive conditions of agricultural civilization, the cultivation technique was very laggard. In spring they have to plough and in autumn they have to harvest, working day and night, having no time to visit friends or relatives. Only on the festival in January in lunar calendar they will have free time. What's more, agreed by mutual consent, the date of duration of the festival in neighboring village are all staggered, so that the villagers have the opportunity to respectively visit their relatives and friends in villages, making it a possibility to meet their friends every year. In order to entertain their friends and relatives, the village also carries out the parade of god and the lanterns, often for all night long. As a result, this has encouraged more relatives and friends to gather together. The rarely comfortable meetings can solve many realistic problems: some will ask for the farming, some will do the business, some talk about the harvest and daily lives. As a result, the annual Lantern Festival is also an annual communication event. For example, during the eighth day of the first lunar month, the famous high ceiling lights were almost out parading overnight. Gongs and drums are aloud, bright lights are everywhere. Countless people are seen everywhere, which is unprecedented. All the villagers and friends and relatives will go out in the unit of the whole family, 
providing people with the opportunity to have full contact with each other, so that their feelings can be deeply communicated and their relationships will be more harmonious. Under the strong festive lantern culture complex, they have greatly promoted the Hakka spirit to further sublimation. It is not only the entertainment about the lanterns, but also the important driving force of the Hakka people.

\section{B. Hakka Festive Lantern Culture Embodies the Diversity of Hakka Culture}

The festive lantern culture based on Hakka farming civilization is a real reflection of the real production and life based on the agricultural civilization, and also the product of adapting to the natural environment and social environment. It has the characteristics of both Chinese culture and Hakka culture. It is generally believed that Hakka culture is a variation of Han culture, which means that Hakka culture is a combination of the central plain culture and indigenous culture. Because of the war and famine, the Hakka people were forced to leave their homeland for generations, but they never changed the way of production and life based on agriculture. Because they leave the Yellow River basin at different times, the basic features and spirit of the central plains culture are different. What's more, the culture of their destinations is different too. The immigrant life has led to the collision and fusion of different regional cultures in different periods, and the resulting Hakka culture including the flower light culture, can be said to be a new culture that takes the essence and discard the dregs. Namely, the central plains culture produced mutation, but has not deviated from the essence of Chinese culture. Its variation is improved in some respects, becoming the new culture or a branch of the Hakka culture. The diversity of these branches together makes up the Hakka culture characteristics.

The connotation of Hakka culture is not necessarily varied, and the part that can adapt to the natural environment and social environment is often completely preserved. As a result, the phenomenon of coexistence between north and south is produced. For example, the big red lantern of these large families of the central plains, is popular with the blessing of farming civilization because of its festive and auspicious colors. Wherever it goes, it retains its original appearance and function. ON the festival it is hung at the gate, or at the wedding ceremony it is carried with the car, even as the representative of Hakka culture, its meaning is self-evident. It was promoted as the embodiment of the Hakka culture. The central plains cultural connotation of the big red lantern has become an integral part of Hakka culture. It makes sense to name it the Hakka lantern.

If the "big red lantern" is the representative of the preserve of Han lanterns, the "dragon lantern" is a good interpretation of the variation of the Han dragon lamps. The Hakka dragon lantern has maintained the atmosphere and majesty of the dragon lantern in the north and has also been integrated into the variety and aura of Hakka dragon lanterns. To say it "nimbus" mainly refers to that the appearance and performance of the paper dragon light is less than the roughness and fierceness of the north but added more delicacy and elegance that the southerners like. For example, the dragon face is kind, the eyes of the dragon are spiritual, the movement of the dragon is soft and beautiful and so on. The "diversity" refers to the Ninghua Hakka also derived to "stem dragon lantern", "bench dragon" and other new lamp species. Paper dragon lanterns only have dragon beads, the dragon head and dragon tail are lanterns made by bamboo paper. Among these, the seven-parted or the nine-parted dragons are all covered and connected by the whole horse ramie cloth. Connecting with lead and the tail, it forms the whole long dragon, so it is also known as the dragon lantern. One of the things that's special about this is that the lights in the dragon lantern are not from candles, but a kind of "oil string" made by the Hakka people. It is made of wool paper inches long and is put into the pot to stew with vegetable oil. With iron clamp installed inside the dragon lantern, the fire is extremely bright. This avoids the lack of the candles and makes the gesture of the dragon swallowing the beads more vivid. It has greatly enhanced the artistic appeal by shaping an original static paper dragon image into a live dragon. The paper dragon lantern can be considered as a medium-sized lamp and is mostly paraded during the Lantern Festival and the Mid-Autumn festival. They might also be put on in some other traditional festivals.

Almost every village has the "Stem Dragon Lantern" in Hakka village. This may because it costs villagers no money. If fact, it is made by incense on the bunch of the straw. The wavering of the incenses at night will display an image of a dragon swallowing beads. Many teenagers are fond of this. It is so deeply self-aware that it does not compete with other beautiful lanterns during the major festivals such as the lunar New Year or during the "spirit festival" after the harvest of late rice. From the first day to the fifteenth day they were paraded once a night to add the happiness of the festival. Hakka people will not be affected because of its making clunky of lanterns but are willing to give a red envelop for its economical quality and vivid images, hoping that it would add some noise to the remote and poor country life. It should be said that the "stem dragon lantern" was born in this environment.

"Bench" dragon lantern in Han is called Candle Bridge lantern. The lamp is located to various images of animals and birds in the wooden bridge frame, one light for one plate, a plate attached to a board, buckling each other like a long bridge. The procession was carried by the strong man, magnificent but costly. After the improvement is made by the Hakka people, the bridge was changed to "dragon" style, not only simple and easy-made, but also practical and spectacular. What's more, it has a promotion in belief. It receives a twometer long bench, with a round hole on each end. A wooden peg inserted into the hole, the boards can then be connected. The lateral rotation is very flexible, with the head and tail, lighting the candle or oil string from beginning to end, forming a long dragon. In Hakka, ancestral homes have two long benches placed at the hall on both sides, which is commonly known as "skirt stool". It is convenient for people to sit at ordinary times. At banquets it can be used as the bench connecting two square tables. It can also be used as an accompanying stool for drummers. It is a genius design to drill a round hole at each end, which is very obvious. To make the dragon tour more sublime and to show people the flourishing of a family and a race, the bench dragon in Cao Fang stipulated 
that the number of the boards should be concord with the number of the males. With more people are born, the number of boards are increasing. The body of the dragon is as long as several hundred meters, forming a strong team of the dragon and the people. In the vast shadow of night wander a dragon in the field buildings, wax light flashing, winding, which makes the person feel the strength of an unyielding rushing in the darkness, and at the same time feels the Hakka people, with an unyielding spirit. Although the production of the "bench dragon" is so simple, the Hakka people don't take it for granted, and it is held every year for its deep meaning. The Hakka's special immigrant life, low level of farming, and their low level of living led to their admiration for the hard and simple fashion. It has led to their enthusiasm for "stem dragon lantern" and "bench dragon", which also promoted the generation and development of Hakka lanterns such as "stem dragon lantern" and "bench dragon".

\section{The Culture of Hakka Festive Lantern Seeks Development in the Spirit of Hakka}

Hakka lanterns culture is produced in a special social background. In order to adapt to the natural environment and social environment, Hakka ancestors integrated the Han lanterns culture from the central plain with the local culture, thus forming the strong regional and dedicate Hakka culture to express their own wished and hopes. When we find that a certain cultural phenomenon is not enough to express ourselves, the pragmatic spirit of Hakka will become the driving force of innovation to make it better. For example, the "archway lamp" of the Hakka ancestral stone wall, which was originally static, is not enough to arouse people's thoughts. Therefore, they use the form of songs and dancing to directly express their spiritual repose with the mountain song and the physical actions, becoming an unprecedented combination of light, song and dance. This kind of light dance is usually performed by eight women with lanterns, bouquets, dancing and singing, and singing songs that are popular with Hakka people. There are "ten best men" and "ten girls" who are good at persuading people to be good. There are "the December field songs" and "the song of cattle songs", which describes the labor production. There are "lock songs" with knowledge of nature and geography, "the ancient song of December", and so on. This kind of light and dance has been close to the stage performance, which fully interprets the moral beliefs of the Hakka people and recreates the form of the festive lantern in art, thus achieving the double function of entertainment and enlightenment. In addition, the "Hakka monument" and "family planning blessing" of the above mentioned high ceiling lights are all the family members' bold innovation in the culture and art of festive lanterns. This has made the Hakka lanterns culture advance with the times and taken for our use, with more vitality and are more radiant.

\section{CONCLUSION}

In the Hakka ancestral land, there are usually small floret lamps, which can be used for praying and praying for the life of the Chinese people and the weather, but they are often seen in the scattered villages and are seldom exhibited in one place. Most of them are mainly the large lanterns of a parade, and the floret lamp is often attached to the mother lanterns of a larger scale. The layers of scenes of Huai plateau are almost exhibitions for the small lanterns. Due to the cultural accumulation of the long history, the stories, characters and events that have occurred often lead to the belief of the lanterns and gradually form deep regional characteristics and family characteristics. If someone in the family in history has won in the imperial examination, the art champion will put on the big "dragon gate lamp", the martial champion will put on the big "Guan Yu's sword lantern". As a result, the lamp is getting bigger and increasingly refined, the influence is increasingly deeper.

To this day, the spring breeze of reform and opening has blown the Hakkas' ancestral land and also into the world of lanterns. The Hakka lanterns represented by the high ceiling lamps are constantly updated from the form to the subject, injecting vivid social content, which appears to be a beautiful landscape. We are convinced that the Hakka lantern will definitely take a bigger and firmer step to promote the Hakka spirit.

\section{REFERENCES}

[1] Li Jingzeng, Huang Zongxian, Fujian provincial committee of local Chronicles compiled "Ninghua county annals", Xiamen university press, 2009 .

[2] Li Shixiong, edited the compilation committee of Ninghua county annals, and the chief editor of the local Chronicles of Fujian province, Ninghua county, Fujian people's publishing house, 2012.

[3] Liu Shanqun, Zhang Renfan, "the light of the stone wall", Xiamen university press, 1993.

[4] Liu Shanqun, "Hakka and Ninghua stone wall", Chinese overseas publishing house, 2000.

[5] Zhang Enting, et al. "proceedings of the world symposium on Ninghua stone wall and Hakka world", Chinese overseas publishing house, 1998.

[6] Xu Yuanzhong, "the Hakka heritage of the Hakka, the art of making art and chandelier culture", "the grand view of art", 2007, 2007. 